\title{
Reflexões sobre o programa escolas sustentáveis na política pública de educação ambiental de Ananindeua
}

\author{
Reflections on the sustainable schools program in Ananindeua's public environmental education policy
}

Marilena Loureiro da Silva', Rodolpho Zahluth Bastos", Monica Goreth Costa Ribeiro"II

\section{Resumo}

O presente artigo apresenta reflexões teóricas e resultados para a dissertação de mestrado intitulada: Programa escolas sustentáveis na política pública de educação ambiental no município de Ananindeua: uma análise em três instituições de ensino, apresentada ao Programa de Pós-Graduação em Gestão de Recursos Naturais e Desenvolvimento Local na Amazônia, e versa sobre o programa escolas sustentáveis na política pública de educação ambiental, no município de Ananindeua, no estado do Pará, a partir da análise de unidades escolares públicas: E.M.E.F. João Paulo II; E.M.E.F. Maria do Carmo e E.M.E.F. Lúcia Vanderley (Ananindeua/Pa). A abordagem metodológica qualitativa e quantitativa, com maior ênfase em aspectos qualitativos, sustentada pela fenomenologia da percepção, envolvendo a observação participante, estudo documental, pesquisa bibliográfica, entrevista e a descrição interpretativa baseada nas percepções teóricas e opiniões dos sujeitos envolvidos com o programa em estudo (gestores, coordenadores, professores e alunos). Os resultados indicam que para tornar as escolas destacadas em espaços efetivamente educadores e sustentáveis é necessário a continuidade dos investimentos direcionados aos projetos elaborados nas instituições, também na formação dos atores escolares para que estes adquiram conhecimentos e incluam estas temáticas no currículo das diversas modalidades de ensino ( da educação infantil ao ensino superior), bem como ampliar a comunicação entre os órgãos mantenedores visando o fortalecimento do trabalho na gestão escolar com foco na educação ambiental.

Palavras-chave: Escolas sustentáveis; Educação ambiental; Políticas públicas

\section{Abstract}

This article presents theoretical reflections and results for the master's dissertation entitled Programa escolas sustentáveis na política pública de educação ambiental no município de Ananindeua: uma análise em três instituições de ensino, it is presented to the Graduate Program in Natural Resource Management and Local Development in the Amazon, and it is about the sustainable schools program in the public policy of environmental education, in the municipality of Ananindeua, state of Pará, from the analysis of public school units: E.M.E.F. João Paulo II; E.M.E.F. Maria do Carmo and E.M.E.F. Lúcia Vanderley (Ananindeua/Pa). The qualitative and quantitative methodological approach, with greater emphasis on qualitative aspects, supported by the phenomenology of perception, involving a participant observation, documentary study, bibliographic research, interview and interpretative description based on the theoretical perceptions and opinions of the subjects involved with the program under study (managers, coordinators, teachers and students). The results indicate that in order to make the highlighted schools in effectively educative and sustainable spaces it is necessary the continuity of the investments directed to the elaborated projects in the institutions, also in the training of the school actors so that they acquire knowledge and include these themes in the curriculum of the various teaching modalities (from early childhood education to higher education), as well as broaden the communication between the maintaining organs aiming at the strengthening of the work in the school management with focus in the environmental education.

Keywords: Sustainable schools; Environmental education; Public policy 


\section{Uma breve introdução}

Observações feitas em um mundo permeado de culturas, tecnologias, ideologias que culminam com diversas ideias, e considerando as concepções de Santos (2006) e Leff (2011), observa-se que as transformações ecológicas desencadeiam problemas de ordem econômica, social, cultural gerando situações que merecem atenção em virtude das relações mantidas entre as pessoas no meio ambiente. Vivenciamse hoje mortes marinhas, um acelerado desmatamento, poluição do ar e do mar, gerando impactos alarmantes em todos os seres humanos, assim como, a desvalorização da fauna e da flora nas sociedades humanas, vide os relatórios dos principais organismos internacionais sobre essas questões. Grimm, Dias, Sampaio e Fernandes (2015) já chamavam a atenção para essa problemática em contraposição ao modelo desenvolvimentista neoliberal, sinalizando a necessidade de privilegiar alternativas capazes de induzir à práticas de base ecológica.

É necessário encontrar formas de criar espaços educadores sustentáveis ${ }^{\mathrm{I}}$ para tornar a sociedade mais igualitária e controlar a degradação do meio ambiente promovendo qualidade de vida. Neste sentido, tornar a escola e outros espaços sustentáveis implica num esforço coletivo, integrado e eminentemente interdisciplinar, o que é um desafio a ser superado, na concepção de Guimarães (1995, p. 55)

[...] a abordagem interdisciplinar objetiva superar a fragmentação do conhecimento. Portanto, esse é um importante enfoque a ser perseguido pelos educadores ambientais, já que permite, pela compreensão mais globalizada do ambiente, trabalhar a interação em equilíbrio dos seres humanos com a natureza.

O presente trabalho traz a luz uma reflexão acerca de assuntos que envolveram educação e sustentabilidade observados em três escolas públicas: E.M.E.F. João Paulo II; E.M.E.F. Maria do Carmo e E.M.E.F Lúcia Vanderley, na cidade de Ananindeua/Pará, visando responder a seguinte questão-problema: Como é desenvolvido o programa escolas sustentáveis na política pública de educação ambiental no município de Ananindeua?

Assim o referencial teórico foi cuidadosamente e a análise dos resultados da pesquisa objetivaram o descortinamento do programa a luz da fala e das práticas dos sujeitos envolvidos em sua realização em cada escola estudada, com a pretensão de auxiliar em futuras pesquisas voltadas não somente no âmbito da educação, mas, também em outras áreas de conhecimento.

\section{A pesquisa}

A pesquisa foi realizada a partir de abordagem qualitativa (SANTOS FILHO; GAMBOA, 1995, p.42), sustentada pela Fenomenologia, com delineamento metodológico adaptado de Stake (1998) e André (2005), descritos por Triviños (1987).

O estudo foi realizado entre os anos 2016 e 2017 junto à gestão de três escolas municipais: E.M.E.F. Lúcia Wanderley (Ananindeua), localizada numa área verde, com sua sede em um bairro urbanizado; E.M.E.F. Maria do Carmo, a instituição se localiza em um bairro antigo no qual a sua implantação teve origem, o entorno da escola é formado por ocupações irregulares onde as pessoas apresentam condições de vida precárias; E.M.E.F. João Paulo II, a escola está situada em uma área urbanizada, próximo de posto de saúde, supermercados, farmácias, lanchonetes, consultórios, lojas. O critério que motivou a escolha de tais espaços foi o fato de se constituírem em locais que estimulam a discussão sobre Educação Ambiental para a comunidade escolar e do entorno e por terem em sua proposta educativa a preocupação com a sustentabilidade, conforme identificado em seus projetos pedagógicos e nas indicações da secretaria municipal de educação de Ananindeua.

O processo de informação envolveu a pesquisa bibliográfica (GIL, 2002), pesquisa documental e pesquisa de campo, nos espaços pesquisados, estudo documental em revistas especializadas em educação ambiental, documentos oficiais do Ministério do Meio Ambiente, Proposta Curricular Municipal e entrevistas com gestores, coordenadores, professores e alunos desses espaços. Na E.M.E.F. Lúcia Wanderley a gestão é a responsável por coordenar as ações educativas sob a orientação da Secretaria Municipal de Educação que segue os encaminhamentos propostos pelo Ministério da Educação. Na E.M.E.F. Maria do Carmo a gestão é a responsável por envolver a comunidade escolar na temática ambiental através das orientações da Secretaria de Educação que obedecem às diretrizes do Ministério da Educação. Na E.M.E.F. João Paulo II, a gestão escolar está sob o comando da Secretaria de Educação que obedece às orientações do Ministério da Educação, trabalhou a Educação Ambiental e sustentabilidade no contexto escolar. As entrevistas, obedeceram aos preceitos éticos e assinatura do Termo de Consentimento Livre e Esclarecido (TCLE), foram realizadas in locu, nas dependências de cada instituição, gravadas e transcritas na íntegra. Houve também a descrição, interpretação e discussão das informações, tendo como base bibliográfica as produções focadas em educação ambiental, sustentabilidade e políticas públicas brasileiras e documentos internacionais, legislações e programa do governo federal. Leff (2003), Santos (2006), Morin (2011), Loureiro (2006), Guimarães (2017; 2003), Silva (2008), Lima (1999), Brasil (2006, 2009, 2013), Carvalho (2011), Pedrini e Saito (2014), Bianchi (2016). As interpretações dos resultados das entrevistas supracitadas ocorreram a partir das adaptações de Santos Filho; Gamboa (1995), Stake (1998) e André (2005). 
3 Dialogando com a gestão sobre as práticas de Educação Ambiental na escola

As três escolas pesquisadas apresentam singularidade de contexto em relação as suas origens, metodologias de trabalho e concepções acerca da educação ambiental, tanto na questão metodológica desenvolvida desde a educação infantil perpassando pelo ensino fundamental maior e menor, chegando à educação de jovens e adultos. Essas se fundamentam nas referências teóricas direcionadas a partir de encaminhamentos previstos pelas suas respectivas propostas curriculares mantidas pela rede municipal de ensino. Também revelam igualdade nos seus objetivos de ação, configurando diversas áreas de conhecimento e atuação abrangendo a educação ambiental e a sustentabilidade no decorrer de todo ano letivo vigente. $\mathrm{Na}$ busca de promoverem mudanças de comportamento nos atores envolvidos com a educação, vivenciando complexas situações que envolvem natureza e sociedade, fomentando e estimulando a humanização, visando a construção de um meio social sustentável.

A seguir serão apresentados e discutidos alguns resultados apontados pela pesquisa acerca dos aspectos: diálogo com a gestão, discussão com docência, concepção dos alunos, com vistas a contribuir com quem atua na área de educação e em especial a educação ambiental.

\section{Quanto ao diálogo com gestão escolar}

Diante das falas das gestoras fica claro que seus conhecimentos ainda são limitados voltados para algumas situações que envolvem o estudo sistemático e pontual com pouco embasamento teórico, muito próximo das constatações de Guimarães (2012, p. 74) em seus estudos. Em se tratando de professores do ensino fundamental, caberia às secretarias desenvolver projetos de avaliação quanto a procedimentos pedagógicos do professor (metodologias, relação professor-aluno, conteúdos desenvolvidos, relação estabelecida com outras áreas de conhecimento) e, se possível, quanto aos valores construídos pelos alunos, com repercussão em seus comportamentos, valores e atitudes. Vale ressaltar que isso exigiria uma formação continuada dos professores, assim como um projeto pedagógico bem definido (BRASIL, 2001, p. 50).

No caso da escola E.M.E.F. João Paulo II constatou-se a necessidade de repensar dentro da proposta municipal de educação o desenvolvimento de ações que podem ocorrer por meio da revisão do Projeto Político Pedagógico como forma de ampliar categorias como: participação em seminários, congressos e conferências para que os profissionais da educação possam desempenhar melhor suas funções e melhor discutir sobre assuntos que envolvam o meio ambiente, mais empenho da gestão escolar para motivar o desenvolvimento do trabalho coletivo, revisão e atualização continua do currículo escolar para a promoção da interdisciplinaridade, liberação de mais recursos financeiros entre os Ministério da Educação e Secretaria de Educação para garantir a perenidade das ações e atividades desenvolvidas na escolas no decorrer do ano letivo visando o sucesso das práticas em Educação Ambiental. Este movimento em busca de sustentabilidade vem ao encontro dos estudos de Guimarães (1995, p.55) que constata:

[...] a abordagem interdisciplinar objetiva superar a fragmentação do conhecimento. Portanto, esse é um importante enfoque a ser perseguido pelos educadores ambientais, já que permite, pela compreensão mais globalizada do ambiente, trabalhar a interação em equilíbrio dos seres humanos com a natureza.

Grün (1996) fala da impossibilidade radical de promover uma Educação Ambiental, quando "fundados [os currículos] nas estruturas conceituais atomísticas e reducionista do modelo cartesiano-newtoniano". Em virtude disso, "os currículos estão longe de representar condições satisfatórias para uma compreensão adequada das realidades de um ambiente limitado" (GRÜN, 1996, p.52).

Sobre o trabalho coletivo visando o sucesso escolar, Placco (2003) escreve que:

Só quando existe uma real comunicação e integração entre os atores do processo educativo há possibilidade de emergência de uma nova prática docente, na qual movimentos de consciência e de compromisso se instalam e se ampliam, ao lado de uma nova forma de gestão e uma nova prática docente. Sobre a categorização do trabalho coletivo foi constatado que a opinião dos pesquisados merece atenção pois é correto afirmar que a educação não se faz por si só, sendo um processo dinâmico ela sempre dependerá de vários fatores para se desenvolver. Em se tratando de escola sustentável, é dada uma atenção maior ao coletivo pois todos precisam se envolver com esta prática, saindo da zona de conforto. Cabe a escola buscar ações para reverter este quadro de desconhecimento por parte dos docentes, já que é deles a responsabilidade de levar os alunos a avançar no conhecimento sobre vários pontos de vista, inclusive, da questão ambiental [...] (PLACCO, 2003, p. 52).

\section{Quanto ao posicionamento dos órgãos executores}

A primeira edição do PDDE Escolas Sustentáveis, ocorrida em 2013, foi regulamentada pela Resolução/ CD/FNDE/MEC no 18/2013 e beneficiou, num primeiro momento, oito escolas do município, e no ano de 2014 com a Resolução/CD/FNDE/MEC no 18/2014 ocorreu a adesão de mais cinco escolas da rede. Diante deste cenário, segundo dados do campo, do universo de treze escolas habilitadas, nove escolas receberam a verba federal e quatro escolas, até o mês de março do ano de 2015, ainda se encontravam com status de "validado pelo MEC", porém sem recebimento da verba federal. Fazendo um recorte para o universo de estudo, as escolas E1, E2 e E3, isso se fez refletir no universo de estudo onde as escolas E1 e E2 receberam a verba do PDDE Escolas Sustentáveis, porém essas parcelas (P1 e P2) saíram com 
bastante atraso. A escola E3 foi uma das quatro escolas que até o ano de 2015 ainda não havia uma confirmação de recebimento desta verba.

Bianchi, (2016) nos convida a refletir sobre a seguinte questão:

[...] são muitas as dificuldades e fragilidades organizacionais, estruturais, políticas e econômicas do Programa Nacional Escolas Sustentáveis: falta de equipe na Coordenação Geral de Educação Ambiental; não institucionalização do Programa Nacional Escolas Sustentáveis oficialmente; não há garantias de orçamento para o universo das escolas; há falta de articulação interna no Ministério da Educação e Cultura para internalizar a proposta nas demais políticas voltadas à educação básica e superior etc. (BIANCHI, 2016, p. 84)

Para o professor 8 o entendimento sobre o que vem a ser escola sustentável é o seguinte:

Você acha que os professores e a escola estão preparados para o Programa Escolas Sustentáveis?

- Algumas sim, mas esbarram na falta de recursos para aplicação dessa atividade, mas mesmo assim desenvolve. (P8) ${ }^{\mathrm{II}}$

Para o entrevistado a escola não se desenvolve sozinha ela precisa de outros atores, executores do processo ensino e aprendizagem. Talvez seja por isso tão difícil que ela permaneça sustentável em virtude também de fatores financeiros que esses ampliam as possibilidades de um fazer pedagógico dinâmico e inovador que tenha o compromisso não apenas com a transmissão de conhecimento, mas especialmente que tenha a preocupação com a formação pessoal, social e ambiental com foco em práticas cotidianas saudáveis e inteligentes. Para tanto, se faz necessário o olhar para o Programa Escolas Sustentáveis visando alcançar objetivos em tempo previsto.

Neste sentido que Bianchi (2016. p.89) ressalta "que professores e escolas aderem às ideias da escola sustentável independentemente de recursos disponibilizados ou apoios, mesmo sem estarem preparados. Entende que a proposta é uma dimensão da educação que pensa também as relações entre os seres vivos, entre a espécie humana e os demais seres vivos. O PNES insere o currículo numa perspectiva socioambiental crítica e transformadora. Vêse outra potencialidade: a oportunidade de aprofundar a questão das territorialidades e os conceitos de sustentabilidade, que têm sido construídos isoladamente".

\section{Quanto a formação de professores em} Educação Ambiental

O entrevistado e docente da escola demonstrou dúvidas e desânimo com os problemas que permeiam

"Resposta obtida em entrevista de pesquisa de campo, com professores nas escolas selecionadas. a formação docente dando ênfase para a questão da estrutura física e humana para trabalhar com um currículo que se movimente em direção a educação ambiental com foco na sustentabilidade visando levar todos os atores escolares a compreensão adequada a cerca de uma educação voltada à sustentabilidade por meio da ação refletiva no conhecimento da sociedade local.

A formação baseada em situações problemáticas centrada nos problemas práticos responde às necessidades definidas da escola. A instituição educacional converte-se em um lugar de formação prioritário mediante projetos ou pesquisas e ações frente a outras modalidades formadoras. A escola passa a ser foco do processo “ação-reflexão-ação" como unidade básica de mudança, desenvolvimento e melhoria. É correto pensar que a formação dos profissionais da escola especialmente dos professores contribui na promoção da autonomia ampliando as condições para a produção do conhecimento (IMBERNÓN, 2009, p. 56).

O exercício da docência eminentemente diretivo tem marcado práticas complexas direcionadas para as diversas disciplinas, no qual o ensino é compreendido como transmissão de conteúdo, memorização de reprodução de informações sistematizadas que contribuem para a retenção de saberes pelo educando. É preciso repensar o papel do professor porque ele é o investigador, o esclarecedor e o organizador de experiências significativas de aprendizagem. Seu compromisso é o de agir refletidamente, criando e recriando alternativas pedagógicas adequadas a partir das experiências que os alunos já trazem promovendo sempre ações interativas (SAVIANI, 2005, p.22).

Embora o entrevistado tenha clareza da importância da formação continuada em serviço para o trato com a questão ambiental nota-se que cabe a escola estar dialogando continuamente com a Secretaria de Educação, a Secretaria de Meio Ambiente e órgãos afins, visando organizar o quadro funcional com técnicos especializados na área ambiental, pois estes com os conhecimentos específicos que possuem certamente podem contribuir no âmbito de todas as disciplinas fazendo com que o saber em relação ao ambiente se torne contextualizado e interdisciplinar.

[...] Faz-se necessário, também, o intercâmbio entre formação inicial e formação continuada, de maneira que a formação dos futuros professores se nutra das demandas da prática e que os professores em exercício frequentem a universidade para discussão e análise de problemas concretos da prática [...] (LIBÂNEO, 2001, p. 11).

“A Educação Ambiental é território de todos e deve ser trabalhada com responsabilidade a partir de uma visão de mundo e sociedade que está inserida no projeto político pedagógico do espaço no qual atuamos" (CAVALCANTE, 2005, p. 122).

[...] Educação Ambiental é uma maneira de educar e se educar com o nosso pequeno planeta azul em mente. A Educação Ambiental pode ser realmente transformadora 
ao trazer novas maneiras de conviver com o mundo em sua totalidade e complexidade, respeitando as diversas formas de vida, cultivando novos valores e criando uma cultura de paz. Mas para que isso aconteça, precisamos ter uma postura observadora e crítica, estudar como a nossa sociedade foi se constituindo ao longo da sua história e adotando comportamentos de uso e abuso dos sistemas vivos [...] (BRASIL, 2012, p.14).

As Diretrizes Curriculares Nacionais de Educação Ambiental indicam que os planejamentos curriculares em acordo com a gestão institucional de ensino devem levar em consideração os saberes e os valores da sustentabilidade, a diversidade de manifestação da vida, assim como também devem:

"contribuir para a revisão de práticas escolares fragmentadas buscando construir outras práticas que considerem a interferência do ambiente na qualidade de vida das sociedades humanas nas diversas dimensões local, regional e planetária” (BRASIL, 2013, p. 552).

\section{Quanto a concepção dos alunos em relação a Educação ambiental}

Os alunos são atores importantes no cenário ensino aprendizagem e necessitam ter os seus interesses atendidos para obter sucesso no seu aprendizado, desse modo esses sujeitos foram convidados para analisar e avaliar o trabalho desenvolvido no campo da Educação Ambiental nas escolas. Esses atores foram selecionados porque estão diretamente envolvidos com a questão do meio ambiente e com suas opiniões podem contribuir para que novas decisões sejam tomadas no ambiente educativo visando ampliação do conhecimento em Educação Ambiental.

De acordo com o discente da escola pesquisada há projetos de educação ambiental que se desenvolvem muito porque a única coisa que teve de ambiental foi sobre um projeto para ensinar a plantar na horta. Esta fala vem ao encontro do que Libâneo (2005) considera como um desafio:

A elaboração conjunta supõe um conjunto de condições prévias: a incorporação pelos alunos dos objetivos a atingir, o domínio de conhecimento básicos ou a disponibilidades pelos alunos de conhecimentos e experiências que, mesmo não sistematizados, são pontos de partida para o trabalho de elaboração conjunta (LIBÂNEO, p. 167, 2005).

De acordo com os discentes a ausência de conhecimento decorre da concepção fantasiosa da relação entre conhecimento e educação ambiental que é resultante da falta de participação dos alunos na realização dos projetos. Para proporcionar aprendizagens significativas torna-se especialmente útil uma metodologia problematizada - a leitura crítica e reflexiva de seu ambiente natural e social; um método que estabeleça conhecimentos abertos e não "acabados" e que proporcione uma visão ampla e complexa da realidade, de seus problemas e possíveis soluções desde as diversas perspectivas e pontos de vista. Paralelamente, é necessária uma especial atenção às atitudes e ao papel do professorado coordenador do trabalho, dando mais importância às atividades em grupo, à interação e ao diálogo dos educandos (MEDINA, 2011, p. 12).

Para este autor faz-se necessário:

[...] para defender que temáticas transversais como a ambiental não sejam trabalhadas por uma nova disciplina, mas através de projetos, capazes de promover a confluência de conhecimentos e saberes diversos para a emergência de um olhar mais holístico das realidades consideradas e da construção coletiva e cooperativa de soluções para os problemas vividos (OLIVEIRA, 2005, p. 336).

Nessa perspectiva, as escolas sustentáveis são espaços que educam pelo exemplo e tendem a influenciar a comunidade. Está alicerçada em princípios éticos universais e princípios de design baseados na observação e leis da natureza, como instrumentos para uma vida sustentável e harmoniosa com o Planeta. Quando vivenciada no ambiente escolar, propõe uma abordagem pedagógica participativa de construção coletiva do conhecimento; a partir de seus princípios de design, oportuniza ações práticas e teóricas (BIASOLI, 2016, p. 91).

É nesse contexto complexo que aparecem novas dimensões educativas. Em todas elas coloca-se ênfase no comportamento ético e orientado à transformação dos comportamentos: a educação para a paz, para a saúde, a educação do consumidor, a Educação Ambiental que, de certo modo, reúne todas. Essas novas dimensões, por sua vez, obrigam a restabelecer conteúdos, atitudes, metodologias e incluem, em resumo, o sentido e o enfoque da educação, o "para quê", o "para quem” e, naturalmente, o “como’ educar. (MEDINA, 2011, p.22)

Sobre a integração da escola com a comunidade buscando discussão sobre educação ambiental, o discente entrevistado salientou:

"Foi mais professor/aluno, não notei a participação da comunidade na escola" (A2).

"Aqui é muito difícil essas coisas, sinto falta porque é um meio de todo mundo se ajudar e não ocorre" (A3).

"Não vi integração do projeto com a comunidade" (A6).

Também, no entender do entrevistado os processos educativos tradicionais estão enraizados nas práticas pedagógicas dos professores, transformando o processo ensino-aprendizado complexo, refletindo de forma negativa no ensino dos conteúdos relacionados ao ensino de educação ambiental. Como bem explica Guimarães (2012):

[...] a Educação Ambiental é uma prática pedagógica que não se realiza sozinha, mas nas relações do ambiente escolar, na interação entre diferentes atores, conduzida por um sujeito: o professor. No entanto, esses professores que estão nas salas de aula ou em formação nas universidades estão se sentindo compelidos, por toda uma demanda social e institucional, a inserir a dimensão ambiental em suas práticas pedagógicas, 'no entanto, essas professoras foram ou estão sendo formados, em sua maioria, na mesma perspectiva conservadora de educação que reproduz $a$ e se reproduz 
na armadilha paradigmática (GUIMARÃES, 2012, p. 124).

Outra questão importante que emergiu do relato dos discentes pesquisados foi a sua não integração do projeto da horta com a comunidade. Apenas num projeto de ação social. O mesmo ainda relata que não sentiu muita integração da comunidade com a escola no desenvolvimento dos projetos de EA, como lembra Libâneo (2005):

O trabalho de planejar as aulas, traçar objetivos, explicar a matéria, escolher métodos e procedimentos didáticos, dar tarefas e exercícios, controlar e avaliar o progresso dos alunos destina-se, acima de tudo, a fazer progredir as capacidades intelectuais dos educandos. Para enfrentar essa tarefa o professor se defronta com algumas dificuldades. Se ele não domina o conteúdo da matéria que ensina, não saberá conversar com os alunos sobre os conhecimentos e experiências que trazem para a sala de aula, terá dificuldades para ligar o conteúdo a aspectos da realidade e ao cotidiano da vida, não saberá relacionar entre si os assuntos das unidades do programa (LIBÂNEO, 2005, P. 105).

Sobre as relações entre a sociedade e meio ambiente, merece destaque a análise de uma experiência desenvolvida no Brasil, especialmente, na região amazônica, discutida por SILVA, 2008, acerca do Projeto de Apoio ao Manejo florestal Sustentável na Amazônia - PROMANEJO - que sugere a conscientização ambiental para o desenvolvimento de práticas inovadoras que tem como foco o trabalho desenvolvido na Floresta Nacional do Tapajós, que valorizou o conhecimento dos atores locais e seus saberes acerca do contexto regional. Esse trabalho foi relevante para o contexto de nossas discussões porque focalizou a importância dos programas de educação para a preservação da Amazônia, visando garantia da qualidade de vida destes moradores na colaboração e interação para fomentar a discussão sobre sustentabilidade.

O relato acima citado sugere reflexões dentro da uma proposta de educação e sustentabilidade, tendo em vista que Guimarães (2012) entende que:

A Educação Ambiental crítica tem um papel decisivo no sentido de contribuir para ampliar a consciência crítica dos indivíduos para a necessidade de construção de uma nova ordem sociometabólica sustentável e de um saber ambiental. Isso significa uma opção por uma Educação Ambiental transformadora e emancipatória que vai além de "ensinar" bons comportamentos em relação à natureza e ao meio ambiente. É uma Educação Ambiental comprometida com as mudanças de valores e a transformação da sociedade (GUIMARÃES, 2012, p. 150).

As informações e relatos apresentados mostram que para tornar as sociedades mais sustentáveis se faz necessário que todos participem, defendam as mesmas ideias, posicionamentos e propostas para sanar conflitos socioambientais que influenciam profundamente na relação entre ser humano e natureza, fortalecendo interesses particulares que não priorizam necessidades da maioria. Com isso, a educação também sofre influência tanto pela falta de investimentos quanto na formação dos envolvidos com este contexto. Todas essas questões relevam a necessidade de repensar uma educação preocupada com os valores, do ser humano e a vida.

\section{Algumas considerações}

Constatou-se, por meio da pesquisa, que tornar a escola pública um espaço sustentável é um dos maiores desafios da educação na atualidade, uma vez que o entendimento sobre o significado de educação ambiental, de acordo com o contexto apresentado e a realidade a qual o indivíduo está inserido, ganha entendimentos diferenciados. Assim, o entendimento que o indivíduo ribeirinho apresenta sobre sustentabilidade certamente não será o mesmo apresentado por um indivíduo urbano, entretanto, ambos devem ser valorizados e levados em consideração, uma vez que, de um jeito ou de outro, estes indivíduos mantém uma relação dinâmica, complexa, comprometida com o meio ambiente, no qual convivem. No que se refere à educação uma alternativa para tornar as escolas sustentáveis seria investimentos feitos pelos programas com responsabilidade e foco na realidade local, visando o desenvolvimento de projeto em curto, médio e longo prazo de acordo com o currículo escolar.

Acredita-se que os objetivos da escola sustentável devem servir a proposta curricular da instituição, entretanto, esta também deve se comprometer em seus escritos com a sustentabilidade, por conseguinte, desenvolver a conscientização ambiental desde os primeiros momentos de escolarização até o ensino superior permitindo possibilidades de um fazer pedagógico e ambiental significativo, inovador e atraente onde o que for apreendido na instituição de ensino seja colocado em prática, conforme evidenciam os estudiosos Mauro Guimarães, Isabel Cristina de M. Carvalho, Marilena Loureiro da Silva, Edgar Morin e tantos outros. E um referencial de sustentabilidade que agrega, também, a educação, a formação docente e a política socioambiental em seu âmbito local, regional e mundial.

Neste contexto que envolve a educação e sustentabilidade, é possível vislumbrar e considerar vários caminhos permeados por políticas ambientais com foco nas ações humanas, nos diversos contextos sociais, pois esse assunto não pode ser percebido de forma isolada, porque faz parte das relações humanas de forma ampla e abrangente, as experiências das pessoas, ao cuidado, a responsabilidade onde o respeito deve ser prioridade quando falamos em conhecimentos e saberes das comunidades do entorno e locais.

Entre as possibilidades de referências estruturantes, podemos destacar entre as políticas desenvolvidas acerca das Escolas Sustentáveis, como o Programa Nacional Escolas Sustentáveis (BRASIL, 2013) e a Formação em Educação Ambiental e Escolas Sustentáveis (2014). As políticas elencadas precisam ser refletidas, pois infelizmente ainda há muito a ser feito para que teoria e prática caminhem juntas na sociedade, seguindo os 
mesmos caminhos para o trato como a questão ambiental, integrando educação e sustentabilidade, reconhecendo a importância de tornar a escola um espaço realmente sustentável.

Muitas foram as referências teóricas utilizadas para a reflexão, dentre elas, cita-se a proposta de Jacques Delors (2003) que nos permite romper com paradigmas que muitas vezes motivam o desenvolvimento de práticas ambientais isoladas ou desenvolvidas em momentos pontuais quando a mídia dá destaque. Contudo entende-se ser possível aprender a ser, aprender a conhecer, aprender a fazer e aprender a conviver juntos para tornar as experiências e vivências dialógicas e ajudar a tornar a sociedade um lugar realmente sustentável onde todos possam contribuir seja na escola, na universidade, na igreja, na praça e ao mesmo tempo compreender a importância de preservar a vida de diversas formas e sobre vários olhares.

Outro aspecto importante a ser considerado para pensar no contexto da educação ambiental referese a formação pessoal e social dos indivíduos, pois cada um mantém de seu jeito uma relação com o meio ambiente, que se concretiza e se fortalece a partir da importância que é dada a vida, por isso é importante uma conscientização ambiental contínua pois, de um jeito ou de outro, os espaços são sustentáveis, já que estes saberes, inicialmente, começam na vida familiar e se concretizam na escola de várias formas, acabando por se tornar referências para uma vida melhor. Assim, ganha destaque a educação quando este processo se torna um importante recurso para superar desigualdades sociais que acabam influenciando os processos de construção de conhecimento das pessoas trazendo sérias consequências para o local onde vivem.

Dentro desta perspectiva considera-se que os processos educativos formais (saberes sistematizados), e não formais (os que aprendemos em nossas vivencias) são determinantes para a construção de concepções que vão direcionar o modo de ser e estar no mundo, assim como as concepções teóricas de diferentes estudiosos (como Alexandre Pedrini e Michele Saito , que destacam na pesquisa, (2014) podem ser referências porque tratam com propriedade de questões relacionadas aos paradigmas metodológicos e propostas de espaços educadores sustentáveis conforme sugere os documentos legais brasileiros.

Neste sentido, reflete-se sobre a construção da escola como um espaço sustentável que possa dar conta de uma proposta metodológica que valoriza a educação socioambiental, que ajude crianças, alunos, jovens e adultos a ter preocupação com a natureza reconhecendo que esta é o seu porto seguro para toda a existência e que por isso deve ser preservada, cuidada e aproveitada da melhor forma possível, onde o conflito seja resolvido de forma dialógica. Ou seja, para que todos entendam que é necessário a união e a cooperação, e a valorização do ser humano, da fauna e da flora, como parte de um contexto mais amplo que precisa ser conservado.

Assim, a pesquisa aponta que é imprescindível que cada um tome posse de suas responsabilidades entendendo que a natureza é um bem coletivo, mas que para preserva-la é necessário políticas públicas, mais educação com qualidade, rompimento de posturas passivas, e o fortalecimento de ações emancipatórias e transformadoras onde prevaleça não somente o interesse individual mas a união, a cooperação, a comunicação, o compromisso, a responsabilidade e o diálogo, visando sempre o entendimento que a natureza é um bem coletivo e que para assim trata-la, a sociedade precisa afirmar os valores de igualdade e democracia para a garantia dos direitos de todos.

\section{Referências}

BIANCHI, Camila Santos Tolosa. Programa Nacional Escolas Sustentáveis: o fluxo de uma ideia no campo das políticas públicas de Educação Ambiental. 2016. 182f. Dissertação (Mestrado) - Faculdade de Educação, Universidade de Brasília, Brasília, 2016.

BIASOLI, Semíramis Albuquerque. Institucionalização de políticas públicas em Educação Ambiental: subsídios para a defesa de uma política do cotidiano. 2014. 117 f. Tese (Doutorado) - Centro de Energia Nuclear na Agricultura, Escola Superior de Agricultura "Luis de Queiroz", Piracicaba, 2015. Versão revisada de acordo com a resolução COPGr 6018 de 2011.

BRASIL. Conferência Nacional Infanto-Juvenil pelo Meio Ambiente: Mudanças Ambientais Globais. 3. ed. Brasília, D.F.: [s.n.], 2009. Relatório Final.

BRASIL. Conferência nacional infantojuvenil pelo meio ambiente: vamos cuidar do Brasil com escolas sustentáveis. Brasília, DF: MEC; Ministério do Meio Ambiente, 2013. Relatório Final.

BRASIL. II Conferência Nacional Infanto-Juvenil pelo Meio Ambiente. 2. ed. Brasília, D.F.: Órgão Gestor da Política Nacional de Educação Ambiental, 2007. (Série Documentos Técnicos, no 11.).

BRASIL. Lei no 9394, de 20 de dezembro de 1996, estabelece as diretrizes e bases da educação nacional. Diário Oficial [da] República Federativa do Brasil, Brasília, DF, 23 dez. 1996. Disponível em: <http://www. in.gov.br/mp_leis/leis_texto.asp?ld=LEI\%939496>. Acesso em: 22 dez. 2016.

BRASIL. Ministério da Educação. Ministério do Meio Ambiente. Vamos Cuidar do Brasil com escolas sustentáveis: educando-nos para pensar e agir em tempos de mudanças socioambientais globais. Brasília, D.F.: Secretaria de Educação Continuada: Alfabetização, Diversidade e Inclusão, 2012.

BRASIL. Ministério da Educação. Programa Nacional Escolas Sustentáveis. Brasília, D.F.: MEC; Coordenação Geral de Educação Ambiental, 2014. Versão Preliminar, 02 jun., 2014. 
BRASIL. Ministério da Educação. Secretaria de Educação Continuada, Alfabetização e Diversidade. Formando COM-VIDA, Comissão de Meio Ambiente e Qualidade de Vida na escola: construindo agenda 21 na escola. 2 ed. Brasília, D.F.: MEC: Coordenação Geral de Educação Ambiental, 2007.

BRASIL. Ministério do Meio Ambiente. Documentos técnicos da II Conferência Nacional do Meio Ambiente. Brasília, DF: Agenda 21, 2006.

BRASIL. Tratado de Educação Ambiental para Sociedades Sustentáveis e Responsabilidade Global. Disponível em:< www.portal.mec.gov.br>. Acesso em: 23 jan. 2016.

CARVALHO, Isabel Cristina de Moura. Educação Ambiental: a formação do sujeito ecológico / Isabel Cristina de Moura Carvalho - 5 ed. - São Paulo: Cortez, 2011.

CAVALCANTE L.O. Currículo e Educação Ambiental. In: FERRARO JÚNIOR (Org.). Encontros e Caminhos: formação de educadoras (es) ambientais e coletivos educadores. Barsília: MMA, Diretoria de Educação Ambiental, 2005.p.115-126.

DELORS, Jacques. Comissão Internacional sobre Educação para o Século XXI. In: UNESCO. Educação: um tesouro a descobrir. São Paulo: Brasília: Cortez, UNESCO, 2003. 288p.

GIL, Antônio Carlos. Como elaborar projeto de pesquisa. São Paulo: Cortez, 2002.

GUimARÃES, Mauro. A dimensão ambiental na educação/Mauro Guimarães. - Campinas, SP: Papirus, 1995. - (Coleção Magistério: Formação e Trabalho Pedagógico)

GUimarÃES, Mauro. A formação de educadores ambientais/Mauro Guimarães - $8^{\mathbf{a}}$ ed. - Campinas, SP: Papirus, 2012. - (Coleção Papirus Educação)

GRIMM, Isabel Jurema; DIAS, Adriana Pasco; SAMPAIO, Carlos Alberto Cioce; FERNANDES, Valdir. Interdisciplinaridade e práticas pedagógicas no desenvolvimento: análise da experiência da microbacia do Rio Sagrado, Morretes/PR. Ambiente \& Sociedade. (online), v. 18, n. 1, p. 115-134, Mar. 2015. DOI: 10.1590/1809-4422ASOC764V1812015en.Disponívelem: h t t p://www.scielo.br/scielo.php?script=sci_ arttext\&pid=S1414-753X2015000100008\&lang=pt. Acesso em: 23 abr. 2019.

IMBERNÓN, Francisco. Formação permanente do professorado: novas tendências; tradução de Sandra Trabucco Valenzuela. - São Paulo; Cortez, 2010.

LEFF, E. (Coord.). A complexidade ambiental. São Paulo: Cortez. 2003.
LEFF, Enrique. Saber ambiental: sustentabilidade, racionalidade, complexidade, poder. 8. ed. Petrópolis, RJ: Vozes, 2011. 494 p.

LIBÂNEO, José Carlos. Adeus professor, adeus professora? Novas exigências educacionais e profissão docente. 5 ed. - São Paulo: Cortez, 2001. - (Coleção Questão da Nossa Época; v. 67).

LIMA, Maria do Carmo. Brasil: como anda nossa Agenda 21?. Caderno de debate Agenda 21, Brasília, DF: Ministério do Meio Ambiente, v. 8, n. 3, set./dez., 1999.

LOUREIRO, Carlos Frederico B. Trajetória e fundamentos da Educação Ambiental. 2. ed. São Paulo: Cortez, 2006.

LOUREIRO, Carlos Frederico Bernardo; LAYRARGUES, Philippe Pomier; CASTRO, Ronaldo Souza de (Org.). Sociedade e meio ambiente: a Educação Ambiental em debate. 5. ed. São Paulo: Cortez, 2008. 183 p.

LUDKE, Menga; ANDRÉ, Marli Eliza Dalmazo Afonso de. Pesquisa em educação: abordagens qualitativas. 2. ed. São Paulo: EPU, 2013.

MEDINA, N. M. Educação Ambiental: uma metodologia participativa de formação/Naná Mininni Medina, Elizabeth da Conceição Santos. 8 ed. - Petrópolis, RJ: Vozes, 2011.

MORIN, Edgar. Os Sete saberes necessários à educação do futuro. 2. ed., rev. São Paulo: Cortez; [Brasília, DF]: UNESCO, 2011. 102 p

OLIVEIRA, H.T. Transdisciplinaridade. In: FERRARO JÚNIOR (Org.). Encontros e caminhos: formação de educadoras (es) ambientais e coletivos educadores. Brasília: MMA, Diretoria de Educação Ambiental, 2005. p.336.- 343.

SAITO, Carlos Hiroo; PEDRINI, Alexandre de Gusmão (Org.). Paradigmas metodológicos em Educação Ambiental. Petrópolis: Vozes, 2014.

SANTOS FILHO, José Camilo dos; GAMBOA, Silvio Sanches (Org.). Pesquisa educacional: quantidade qualidade. São Paulo: Cortez, 1995.

SAntos Pinto, V. P. dos \& GUimarães, M., A Educação Ambiental no contexto escolar: temas ambientais locais como tema geradores diante das questões socioambientais controversas. Revista de Geografia - PPGEO - UFJF. Juiz de Fora, v.7, n.2, (juldez) p. 149-162, 2017.

SANTOS, Boaventura de Sousa. Pela mão de Alice: o social e o político na pós-modernidade. 11. ed. São Paulo: Cortez, 2006.

SANTOS; Boaventura de Sousa (Org.). Democratizar a democracia: os caminhos da democracia participativa. 2. ed. Rio de Janeiro: Civilização Brasileira, 2002. 
SAVIANI, Dermeval. Pedagogia histórico crítico: primeiras aproximações. 9. ed., Campinas: Autores Associados, 2005.

SILVA, Marilena Loureiro da. Educação Ambiental e Cooperação Internacional na Amazônia. Belém: NUMA/ UFPA, 2008.

STAKE, R. E. Case studies. In: DENZIN, N. K.; LINCOLN, Y. S. (Ed.). Handbook of qualitative research, Thousands Oaks, Sage, 1998.

TASSARA; Eda. Dicionário socioambiental: ideias, definições e conceitos. São Paulo: Faarte, 2008.

TRAJBER, Rachel; MENDONÇA, Patrícia Ramos (Org.). O que fazem as escolas que dizem que fazem Educação Ambiental. Brasília, D.F.: Ministério da Educação, 2006.

TRAJBER, Rachel; SATO, Michèle. Escolas Sustentáveis: incubadoras de transformação nas comunidades. REMEA Revista Eletrônica do Mestrado em Educação Ambiental, v. especial. set. 2010. DOI: https://doi.org/10.14295/remea. v0i0.3396. Disponível em: https://periodicos.furg.br/remea/ article/view/3396. Acesso em: 23 jun. 2019.

TRIVIÑOS, Augusto Nibaldo Silva. Introdução à pesquisa e ciências sociais: pesquisa qualitativa em educação. São Paulo: Atlas, 1987. 